\title{
Toplumsal İletişim Bağlamında Kütüphaneler: Kavramsal Bir Değerlendirme
}

\section{Libraries in the Context of Mass Communication: A Conceptual Evaluation}

\section{H. Buluthan ÇETINTAŞ̧*}

Öz: Bilgi çağıyla birlikte, bilgiye ihtiyaç duyan, ihtiyaç duyduğu bilgiyi en doğru ve güncel hali ile hızlı biçimde temin etmek isteyen bireylerden meydana gelen bir toplum biçimi oluşmuştur. Bilgi toplumu olarak adlandırılan bu toplum, araştıran, düşünen, sorgulayan ve analiz edebilen bireylerden oluşmakta ve bilgi ihtiyacı, toplumsal yaşamın bir gereksinimi olarak ortaya çıkmaktadır. Toplumsal bilgi ihtiyacını hızlı ve güvenilir bir biçimde karşılamak, kütüphanelerin görevleri arasında yer almaktadır. Bu açıdan kütüphaneler, kişilerin bilgi kaynaklarına erişmesine olanak sağlayan kurumlardır. Bilgi toplumu ile önemi artan bir başka unsur, iletişim kavramıdır. İletişim, bilgi paylaşımı süreci olarak kişisel ve toplumsal yaşamı sürdürmenin temel aracı olarak kabul edilmektedir. Bu kapsamda kütüphaneler, toplumsal iletişim sürecinin gerçekleşmesine katkıda bulunan kurumlar olarak bir yandan bireylerin bilgi ihtiyacını karşılamakta diğer yandan toplumsal iletişimin gerçekleşmesinde önemli bir rol üstlenmektedir. Zira kullanıcılar ile iletişim kurmak, kütüphanede gerçekleşen çalışmaların önemli bir parçasıdır. Tam bu noktada kütüphaneler, önemli bir misyon üstlenerek eğitim sürecinde olan ya da olmayan herkese ve her yaş grubuna hitap eden, her çeşit bilgiyi ve bilgi kaynağını sunmasıyla toplumsal iletişimin önemli bir parçası haline gelmiştir. Derleme niteliğindeki bu çalışmanın amacı, kavramsal olarak kütüphanenin toplumsal iletişim sürecindeki rolünü irdelemek, bir kurum olarak kütüphanede gerçekleşen iletişimi ele almak, iletişim ve kütüphane kavramlarına ilişkin çeşitli saptamalarda bulunmaktır.

Anahtar sözcükler: İletişim, Kütüphane, Örgütsel İletişim, Sosyal İletişim, Toplumsal İletişim

\begin{abstract}
With the information age, a form of society has emerged that thinks it needs information and provides the information in the most accurate and latest form. This society, called the information society, is made up of individuals who search, think, inquire and analyze, and the need for information arises as a necessity of social life. Meeting the need for social information in a fast and reliable way is among duties of libraries. In this respect, libraries are organizations that allow people to access information sources. Communication is regarded as the main means of continuing personal and social life as an information sharing process. The library needs to have access to qualified sources of information for evaluating users' leisure time and using them in their research. In this context, libraries play an important role in fulfilling the information needs of the individuals, as institutions contributing to the social communication process and in the realization of social communication. This because communicating with users is an important part of the work in the library. At this point, libraries are organizations that are an important part of social communication, capable of presenting all kinds of information and information sources, addressing all age groups and everyone. The purpose of this review study is to conceptually examine the role of the library in the social communication process, to discuss organizational communication in a library, and to make various determinations about concepts of communication and the library.
\end{abstract}

Keywords: Communication, Library, Organizational Communication, Social Communication, Mass Communication

* Dr. Öğr. Ü., Atatürk Üniversitesi, Bilgi ve Belge Yönetimi Bölümü, Erzurum. bcetintas@gmail.com 


\section{Giriş}

Sosyal bir varlık olan insanın yaşamını sürdürebilmesi için iletişim kurması gerekmektedir. İletişim, bilgi paylaşımı süreci olarak kişisel ve toplumsal yaşamın sürdürülmesinin temel aracı olarak kabul edilmektedir. İnsanlar gibi toplumların da iletişim kurma ihtiyacı vardır. Toplumlar, iletişim aracılığıyla var olur, büyür ve gelişirler (Usluata 1995, 10). Gerek bireysel gerekse örgütsel iletişim becerilerinin önem kazanması, çağımızın en önemli özelliğini oluşturmaktadır. Bugünün bilgi çağı, küresel ölçekte yeni bir örgüt biçimini tanımlamakta ve belirlemektedir. Bu biçim, bilginin bireyler ve örgütler arasında sürekli ve etkileşimli şekilde yönetilmesini vurgulamaktadır (O'Hair et al.2005, 3).

Bilgi iletişiminin ve paylaşımının ön plana çıkması, bilginin önemini artırmaktadır. Gelişmiş toplumlar, bilgiyi üretmekte ve bilginin gücünü elinde tutmaktadır. Bilgi çağı ile birlikte, bilgiye ihtiyacı olduğunu düşünen, ihtiyaç duyduğu bilgiyi en doğru ve güncel hali ile hızlı biçimde temin etmek isteyen bir toplum oluşmuştur. Bu toplum, bilgi toplumu olarak adlandırılmaktadır. Bilgi toplumu, araştıran, düşünen, sorgulayan ve analiz edebilen bireylerden oluşmakta ve bilgi ihtiyacı, toplumsal yaşamın bir gereksinimi olarak ortaya çıkmaktadır (Rukancı \& Anameriç 2004, 335). Günümüzde bilginin değerindeki ve hacmindeki artış, ticari başarıları belirlemekte ve etkilemektedir. Bilgi çağının başarılı örgütleri, çalışanları yeni teknolojilere uyum sağlayabilen, bilgiyi etkili biçimde yönetebilen, teknolojinin yardımıyla örgütsel iletişimlerini artırmayı hedefleyenler ve bunu gerçekleştirebilenlerdir (O'Hair et al. 2005, 3).

Dünyanın en eski toplumsal kurumlarından olan kütüphanelerin asli görevi, toplumsal hafızayı korumak ve yaygınlaştırmaktır. Ancak kütüphaneler, tarih boyunca farklı görevleri ve işlevleri de yerine getirmiştir. Bir sosyal kurum olarak kütüphane, toplumun politik, ideolojik ve değer yapılarıyla oluşmuş ve toplumun ihtiyaçlarına cevap verebilme yeteneğini kazanmıştır. (Einasto 2015, 247-248). Kütüphanelerin toplumsal rolü ya da amacı olarak tanımlanan aslında kütüphanenin toplumsal bir kurum olarak işlevleri anlamına gelmektedir. Dolayısıyla kütüphaneler, önemli bir misyon üstlenerek eğitim sürecinde olan ya da olmayan herkese, her yaş grubuna hitap edecek şekilde, her çeşit bilgiyi ve bilgi kaynağını sunabilen, bu haliyle toplumsal iletişimin önemli bir unsuru olan kurumlardır. Bilgi toplumunun gelişimi, kütüphanelere yeni firsatlar sunmakta ve onlar için yeni misyonlar belirlemektedir. Misyon ne olursa olsun kütüphanenin doğası, iletişimsel olup, temel amacını iletişim ile gerçekleştirmektedir.

Bilgi verme ve alma, insanlar ve metinler arasındaki etkileşimler, kütüphaneciler ile kullanıcılar arasındaki etkileşimler, vb. iletişim süreçleri kütüphanelerde her zaman gerçekleşmektedir. Ayrıca kütüphane, koleksiyonlarını kataloglarda tanımlayarak, kullanıcı isteklerini cevaplayarak ve kültürel etkinlikleri organize ederek de çeşitli iletişimsel işlevleri yerine getirmektedir (Einasto 2015, 248). İletişim becerileri, bugünün toplumsal yaşamında hiç olmadığg kadar önem kazanmaktadır. Bilginin iletilmesi, analiz edilmesi, kullanılması ve dönüştürülmesi ön plana çıkmaktadır. Bu durum, kütüphanelerin toplumsal iletişimindeki etkisini artırmaktadır. Bu kapsamda kütüphaneler, toplumsal iletişim sürecinin gerçekleşmesine katkıda bulunarak bir yandan bireylerin bilgi ihtiyacını karşılamakta diğer yandan toplumsal iletişimin gerçekleşmesinde önemli bir rol üstlenmektedir.

Literatürde iletişim ve kütüphane kavramları arasında çeşitli ilişkiler kurulmuş ve bu kapsamda çeşitli çalışmalar yapılmıştır. Bu çalışmaları çeşitli başlıklar altında toplamak mümkündür:

- Örgütsel iletişim ve kâr amacı gütmeyen kuruluşlar, Bonk, Tynes, Griggs and Sparks (2008), Patterson ve Radtke (2009), Bryson (2011).

- Kütüphanelerde etkin hizmet vermek için iletişimin gerekliliği ve önemi, Hughes, 
Rockman ve Wilson (2000), Wallis (2005), Li, Wong ve Chan (2010).

- Kütüphanelerde yeni medya araçlarının kullanımı, Farkas (2007), McIntyre ve Nicolle (2008), Nielsen, (2009), Costello ve Bosque (2010), Rodriguez (2010), Grgic (2013).

- Kütüphane içinde ve dişında gerçekleşen iletişim, Jankowska ve Marshall (2004), Li (2006), Brophy (2007), Parrott (2016), Drivas, Sakas ve Giannakopoulos (2016).

- Kütüphanelerde etkin iletişim Gould (2009), iletişim modelinin kütüphaneye uygulanması Afolabi (1993), kütüphane web sayfası aracılığıyla karşılıklı iletişim Agyemang, Boateng ve Dzandu (2015), kütüphane değerlerini iletişim yoluyla aktarma Walter (2018) gibi çalışmalar bulunmaktadır. Kütüphane ile toplumsal (kitle) iletişim konusunu Yılmaz (2003) haricinde doğrudan inceleyen yayına rastlanmamıştır.

Derleme niteliğindeki bu çalışmada, iletişim ve kütüphane ilişkisi kavramsal bir bakış açısıyla değerlendirilmiştir. İki olgu arasındaki ilişki, iletişim türleri ve iletişim araçları göz önünde tutularak belirlenmeye çalışılmıştır. Sonrasında kütüphanelerin toplumsal iletişim sürecindeki rolü, toplumsal iletişim sürecine katkısı ve bu süreç için öneminden bahsedilmiştir. Sonuç kısmında ise genel bir değerlendirme ile toplumsal iletişim bağlamında kütüphaneler konusu ele alınmıştır.

\section{İletişim ve Kütüphane}

İletişim, toplumsal sürecin temelinde yer alan olgulardan biridir. İletişim aracıllğı ile insan, bireysel varlığını ve toplumsal ilişkilerini sürdürmektedir (Aziz 2010, 24). İletişim, insanın fiziksel, psikolojik ve örgütlü varlığını sürdürmesi, yaşanan koşulları tutması, geliştirmesi ve aynı zamanda değiştirmesi için gerekli faaliyetlerin zorunlu bir koşuludur. İletişim, insan faaliyetlerinin her anıyla ve doğasıyla iç içe olan özelliklere sahiptir. İnsanın kendini maddi ve düşünsel (entelektüel, duygusal, inançsal, ahlaki ve vicdani) olarak yeniden üretmesini içermektedir (Erdoğan 2013, 15-17). İletişim, insan için vazgeçilmez kavramlardan biridir. Kişinin toplum içindeki yaşamını devam ettirmesinin yolu diğer kişilerle sosyal ilişkiler kurması ve bu ilişkileri devam ettirebilmesinden geçmektedir. Öte yandan iletişimin kişilerin diğer bireylerle ilişkilerini düzenleme, iş yerindeki başarısını etkileme, bulunduğu sosyal ortamlardaki mutluluk ya da mutsuzluklarını belirlemede önemli bir etkiye sahip olduğu kabul edilmektedir (Kumtepe \& Küçük 2015, 5).

İletişim, tüm örgütler için önemli ve gerekli bir insani eylemdir, bundan kütüphaneler istisna değildir (Budd \&Velasquez 2014, 394). Diğer herhangi bir örgütte olduğu gibi kütüphaneler de kullanıcılarıyla ilişkilerini devamlı kılmak için etkin iletişim kanalları kurmalı ve bunu sürdürmelidir (Alansari, 2013, 69). Öte yandan örgütsel işleyişin örgütün yapısına ve amaçlarına uygun biçimde gerçekleşebilmesi için örgütün kendine özgü iletişim politikaları geliştirmesi kaçınılmazdır (Güngör 2011, 191). Dolayısıyla bir kütüphanenin öncelikle kendisi için etkili olabilecek iletişim yöntemini belirlemesi gerekmektedir. Bu süreçte belirlenecek iletişim yöntemi, kullanıcı türüne göre farklıl1k gösterebilir. Örneğin yeni bir hizmetin duyurusunda üniversite öğrencilerine ulaşmak için bloglar, web siteleri, e-posta ya da sosyal medya araçları tercih edilebilecekken, daha yaşlı bir kullanıcıyla iletişimde yüz yüze iletişim yöntemi seçilebilir. Aslında en etkili iletişim yöntemi, durumun gerektirdiği şekilde ve o duruma en uygun olan yöntemdir.

Günümüzde kütüphanelerde gerçekleşen iletişim, katılımcı, yatay, dengeli, diyalog temelli ve iki yönlü iletişim gibi çeşitli kavramlarla ifade edilmektedir. İki yönlü iletişim ile amaçlanan bir şeyleri birlikte yapmak, bilgi ya da fikir paylaşımı sağlamaktır. Toplumsal iletişim sürecinin etkin biçimde oluşması, iletişimin temel unsuru ve gereği olan karş1lıklı bilgi alışverişinin başarılı biçimde gerçekleşebilmesine bağlıdır. Etkin iletişim, örgütte bulunan herkese yük getir- 
mektedir ancak bu yük, kütüphanenin amaçlarına ve hedeflerine ulaşması için gereklidir (Budd \& Velasquez 2014, 395).

İletişim, bireysel, örgütsel ve sosyal yaşamın vazgeçilmez aracı ve temel unsurudur. Kişi, gündelik yaşamında diğer insanlarla, kurum ya da kuruluşlarla, gruplarla ya da kendisiyle iletişim kurarak yaşamaktadır (Tutar 2009, 40). Bir toplumsal ilişkiler sistemi olarak iletişim; amacına, yapılma şekline, zamana, mekâna ve kullanılan araçlara göre farklılık gösterebilmektedir. Bu kapsamda iletişim kavramını; içsel iletişìm, kişiler arası iletişim, örgütsel iletişim ve kitlesel iletişim olarak dört grupta incelemek mümkündür. İletişim türleri ve bunların kütüphaneler ile ilişkisi aşağıda verilmiştir:

a. İçsel iletişim: Kişinin içindeki iletişim olarak adlandırılan içsel iletişim, kişinin kendisi ile yaptığı iletişim türüdür. Bu tür iletişim, iletişim ögeleri bakımından tam bir iletişim süreci olmamakla birlikte, iletişimi başlatan ya da alan taraf olan insanın kendi içindeki iletişim olması nedeniyle önem taşımaktadır (Aziz 2010, 50). Birey düşünerek, kişisel ihtiyaçlarının farkına vararak ve sorgulayarak cevap üretmekte böylece kişisel düşüncelerini oluşturmakta ve konulara farklı açılardan yaklaşabilmektedir. Bu nedenle ancak içsel iletişimin olmasıyla kişiler arası iletişim ve diğer iletişim biçimlerinin gerçekleştiği bilinmektedir. Kütüphaneden yararlanma ve kütüphaneyi kullanma düşüncesinin, bu aşamada ortaya çıktı̆g söylenebilir.

b. Kişiler arası iletişim: Kişiler arası iletişim, iletişim olgusunun ve sürecinin tam olarak bulunduğu, insanlar arasında gerçekleşen iletişimdir. Bunun için bir gönderici ve bir hedef olmak üzere en az iki kişi gereklidir (Aziz 2010, 50). Kişiler arası iletişim, genellikle kendiliğinden ve teklifsizdir, katılanlar birbirlerinden en üst derecede geri bildirim alırlar (Tutar 2009, 95). Kişiler arası iletişimle insanlar, çeşitli ilişkiler kurmakta, yürütmekte, geliştirmekte ve sona erdirmektedir. Ayrıca sorunları çözmekte, görevleri yerine getirmekte, kendi gereksinimlerini ve toplumda diğer insanların gereksinimlerini karş1layabilmektedir (Erdoğan 2002, 182). Kişiler aras1 iletişimin öğrenme, iletişim kurma, etkileme, eğlendirme ve yardımcı olma amaçlarına yönelik kullanımı aynı zamanda kütüphanelerin varoluş amaçları arasında da yer almaktadır.

c. Örgütsel iletişim: Örgütsel iletişim, örgütün iç ve dış çevresi ile yapmış olduğu biçimsel iletişimdir (Tutar, 2009, 159). Örgütsel etkinlikleri ve ilişkileri sürdürmek için örgüt içinde çalışanlarla, örgüt dışında ise diğer örgütlerle ilişkilerin kurulması ve sürdürülmesi gerekmektedir. Örgütün oluşması, devamı ve gelişmesi ancak örgütü oluşturan insanların birbirleriyle örgüt içinde ve örgüt dışında iletişimleri ile sağlanabilir (Erdoğan 2002, 265). Dolayısıyla örgütsel iletişim, örgütlerde iş birliği, koordinasyon ve kontrol işlevini yerine getiren örgütsel ve yönetsel yapının en önemli ögelerinden biridir (Gökçe 2010, 178). Bir sistem olarak iletişim olgusunun en büyük amac1, örgütsel ilişkilerin belirli bir düzen içine sokulması böylece örgütsel amaçlarla bireysel amaçlar arasında bilinçli bir dengenin kurulmasıdır (Gürgen 1997, 33).

Bahsedilen durum, bir örgüt olan kütüphaneler için de geçerlidir. Kütüphanelerde her şeyden önce çalışanların etkin iletişim kurması sağlanarak, kütüphanenin amaçlarına ve kullanıcılarına uygun biçimde hizmet verilmesi, örgütsel verimlilik açısından önem arz etmektedir. Öte yandan kütüphanelerin kendi aralarında kuracakları iletişim ile birlikte çalışma, bilgi ve kaynak paylaşımı, personel oryantasyonu gibi çeşitli olanaklar ve fırsatlar gerçekleşebilecektir. Örgütsel iletişimin başka bir boyutu, kullanıcılar ile kütüphaneciler arasında gerçekleşen iletişimdir. $\mathrm{Bu}$ iletişim, özellikle yeni kütüphane kullanıcılarını, kütüphane kuralları ve politikaları, bilgi kaynakları ve hizmetleri hakkında bilgilendirme ile bunlara yönelik eğitim biçiminde görülebilmektedir. 
d. Kitlesel iletişim: Kitlesel iletişim, iletişimin kitle iletişim araçları ile yapılan türüdür. Bu tür iletişimde, yüz yüze ya da diğer iletişim kanalları ile ulaşılamayacak sayıdaki kişilere, kitlesel iletişim araçları kullanılarak mesajlar aktarılır (Aziz, 2010, 51). Günümüzde kitle iletişimini sağlayan araçlar kütüphanelerde sıklıkla kullanılmaktadır. Kütüphane kullanıcıları kütüphaneye gitmeden kütüphanenin sunduğu hizmetlere ve bilgi kaynaklarının çoğunluğuna kitle iletişimi araçları aracılığıyla ulaşabilmektedir. Bilginin üretilmesi, topluma iletilmesi ve toplum tarafindan kullanılması süreci olarak tanımlanabilecek bilgi iletişiminde kitle iletişim araçlarının kullanımı, bilgi iletişim sürecini etkin k1lacaktır.

Yukarıda açıklanan iletişim türlerine dayanarak iletişimin dinamik ve etkileşimli olduğu, içinde ileti, veri, fikir, olgu, haber ve sembol gibi olgular barındırdığı ve tüm bu olguların dikkate alınması gerektiği söylenebilir. Bu nedenle iletişim kavramı üzerinde dururken kütüphanelerde toplumsal iletişim amacıyla kullanılan iletişim araçlarından bahsedilmesi yerinde olacaktır.

\section{Kütüphanelerde İletişim Araçlarının Kullanımı}

Örgütler, varoluş nedenleri ve yapıları ne olursa olsun, varlıklarını bir ilişkiler düzeni içinde sürdürür. $\mathrm{Bu}$ ilişskilerin denetim altına alınması, belirli bir yapısal düzen ve amaç içinde işlemesi ancak iletişim ile sağlanmaktadır (Erdoğan 2013, 129; Tutar 2009, 22). Öte yandan iletişim ile örgütsel planların uygulanması, örgütsel faaliyetlerin eş güdümlenmesi ve bunların görevli kişilere iletilmesi mümkün olabilmektedir. Yine iletişimle çalışanların motivasyonunu artırarak, örgütsel planları istekli biçimde gerçekleştirmeleri sağlanabilmektedir (Can 1999, 254). Bu kapsamda iletişim, çalışanları birbirine bağlayan ve onların ortak bir amaç doğrultusunda çalışmalarını sağlayan bir süreç niteliğindedir. Bu sürecin sağlam ve devamlı olabilmesi için düzenli bir biçimde gerçekleşmesi, gönderilen mesajların anlaşılması ve alınan mesajların bilgi, duygu ve davranış değişikliğine neden olması gerekmektedir (Te’eni 2008, 3004).

Örgütsel iletişim, örgütte gerçekleştirilen tüm faaliyetlerin temelini oluşturmakta ve bu faaliyetlerin yürütülmesini sağlamaktadır. Örgütsel iletişim araçları ise örgütlerde biçimsel iletişimi gerçekleştirmede kullanılan araçlardır. Bu araçlar, örgütsel faaliyetlerin verimli ve etkin bir şekilde yürütülmesinin zorunlu koşulu haline gelmiştir (Tutar 2009, 241). Günümüzde birçok örgütte ve kütüphanede farklı amaçlara yönelik biçimde çeşitli iletişim araçları kullanılmaktadır. Genel olarak bu araçları, geleneksel iletişim araçları ve web tabanlı iletişim araçları şeklinde iki başlikta incelemek mümkündür:

a. Geleneksel iletişim araçları: $\mathrm{Bu}$ araçlar, internet teknolojilerinden fazlaca yararlanmayan, genellikle tek yönlü ve daha çok kitlesel iletişim için kullanılan araçlardır. Geleneksel iletişim araçları, sözlü, yazılı ve görsel-işitsel iletişim araçları olarak üç grupta değerlendirilebilir (Sabuncuoğlu \& Gümüş, 2008, 112):

- Sözlü iletişim araçları: Bir mesajın sözlü olarak iletilmesini sağlayan araçlardır. Yüz yüze ya da telefonla görüşmeler, toplantı ve seminer gibi organizasyonlar, duyurular, vb. bu nitelikte kullanılan iletişim araçlarıdır (Tutar, 2009, 245). Kütüphanelerde kullanılan en temel sözlü iletişim aracı, kullanıcı ile kütüphane personeli arasında gerçekleşen yüz yüze iletişimdir. Bunun yanı sıra telefonla görüşme (bilgi alma, soru sorma, vb. amaçlarla görüşme), sesli mesaj yöntemi ile istenilen bilgi hizmetlerine veya bilgi kaynaklarına ulaşılabilme, bu nitelikte yoğun olarak kullanılan araçlar arasındadır.

- Yazılı iletişim araçları: Örgütler tarafından yayımlanmakta olan dergi, gazete, bülten, broşür, kitapçık, vb. önemli yazılı iletişim araçlarındandır (Yatkın, 2003, 85). Kütüphanelerde yazı11 iletişim araçları eskiden beri kullanılmaktadır. Örneğin bültenler, kütüphane hizmetlerini ve çalışmalarını duyurmak için kullanılan temel yazılı iletişim araçlarından biridir. Broşürler veya 
kitapçıklar ile kullanıcıları, kütüphane bünyesindeki yenilikler ve gelişmeler hakkında bilgilendirmek mümkündür. Kısa mesaj yolu ile kullanıcıları bilgilendirme, uyarı ya da hatırlatma yapma son dönemde sıkça kullanılmaktadır. Yazılı iletişim araçlarını hazırlarken kısa olmasına dikkat edilmeli, ilgi çekici görsellerin yanında kütüphanenin erişim ve iletişim bilgilerine de yer verilmelidir (Siess 2003, 64).

- Görsel-işitsel iletişim araçları: Görüntü ve ses içeriklerinin yoğun olarak kullanıldığı araçlar olup radyo, televizyon ve diğer video biçimleri bu kapsamdadır. Radyo, konuşma, haber ve müzik içeren bir araçtır. Televizyon ise hikâyeleri canlandırmakta, iletilmek istenen mesajı ses ve görüntü ile birlikte vererek daha etkili hale getirmektedir (Moriarty et al. 2012, 369). Bahsedilen iletişim araçlarını kullanarak topluma, kütüphaneler ve kütüphanelerde yer alan materyaller hakkında bilgi vermek mümkündür. Ayrıca ödüllü okuma kampanyaları düzenlenerek toplumun ilgisini kütüphanelere çekmek mümkündür. Bu kapsamda düzenlenecek radyo programları aracılığıyla kütüphane kullanımının ve kitap okumanın gerekliliği ve önemi aktarılabilir. Her yıl düzenlenen Kütüphane Haftası etkinlikleri kapsamında illerde en çok kitap okuyan kişilere yerel ya da bölgesel televizyon kanallarında hediyeler ve teşekkür belgeleri verilebilir. Ayrıca bu tür etkinliklerin yıl içinde tekrarlanması, toplumsal iletişimin sürekliliğini sağlaması açısından yararlı olacaktır.

b. Web tabanlı iletişim araçları: İletişim teknolojilerinin gelişmesi ve yeni teknolojilerin eklenmesiyle zaman ve mekân farklılıkları ortadan kalkmış, insanlar daha az yüz yüze iletişim kurarken, teknolojik araçları kullanarak daha fazla iletişim kurmaya başlamıştır (Güçdemir 2010, 39). Aslında web tabanlı iletişim, kişiler arası ve yüz yüze iletişim tarzlarının yerini tamamen almamakta ancak bu tarz iletişimlerin biçiminde ve gerçekleşmesinde değişikliklere neden olmaktadır. Zira eski/geleneksel medya (konuşma, kitap, radyo, gazete) ortadan kalkmamıştır ve muhtemelen hiçbir zaman da kalkmayacaktır (Poe 2014, 357). Diğer taraftan yeni teknolojiler sadece eski medyanın yeni bir ortama taşınması olmayıp, müşteri ile değişen etkileşim, nesnellik, uygunluk ve güncellik gibi durumlar hakkında farklı standartları içermektedir (Dilenschneider 2010, 3). Yeni dijital medya, görsel-işitsel medyanın yüksek etkiye sahip görselleri, basılı medyanın derinlemesine bilgisini, internetin kişileştirme ve etkileşim özelliklerini bünyesinde barındırmaktadır (Moriarty et al. 2012, 411).

Web tabanlı iletişim araçlarının en popüler olanları sosyal medya araçları ve ortamlarıdır. Sosyal medya araçları, kullanıcıları geri bildirimde bulunmaya teşvik ederek bilginin yayılmasına, paylaşılmasına, yorumlanmasına ve değerlendirilmesine izin vermektedir. Bu araçlar ile iletişim, hızlı bir şekilde gerçekleşmekte, etkili ve çift yönlü bir iletişim ortamı sağlanmaktadır (Güçdemir, 2010, 97). Sosyal medya araçlarının yaygınlaşmasıyla birlikte kütüphanelerde gerçekleşen iletişim biçimlerinde değişimler olmuştur. Sosyal ağlar, kütüphanelerde yer alan kaynaklar, gerçekleşen güncel olaylar, diğer konular hakkında bilgilerin kolayca yayılmasına izin vermektedir (Bernaoui ve Hassoun, 2015, 68). Kütüphaneler, çevrim içi ortamı olabildiğince etkin bir şekilde kullanmaya başlamıştır. Örneğin kütüphane blogları, kütüphaneler tarafından uzun zamandır kullanılan araçlardan biridir. Kütüphaneler, bu bloglarla her türlü duyuruyu yapabilmekte, elektronik kaynaklara erişim sağlamakta ve bilgi kaynaklarına ilişkin bilgilendirmeler yapabilmektedir.

Bilgi ve iletişim teknolojilerinde yaşanan gelişmeler, iletişim araçlarının dijital hale gelmesine neden olmaktadır. Bu tür gelişmelerin kütüphanelere yansıması neticesinde kütüphane ile kullanıcı arasındaki bilgi kaynaklarının iletimi ve kullanımı hızlanmıştır. Hatta kullanıcı, kütüphane hizmetlerinin ve faaliyetlerinin merkezine yerleşmiştir demek yanlış olmayacaktır (Bernaoui \& Hassoun 2015, 68). Bu durum, farklı bilgi hizmetlerinin oluşmasına ya da var olan hizmetlerin biçim değiştirmesine neden olmuş ve kütüphanenin en önemli unsuru olan bilgi 
kaynağına erişimin şeklini değiştirmiştir. Teknolojik gelişmelerin bilgi hizmetlerine katkısı, elektronik dergilere ve pre-print dergilere erişim; sınırlı sayıda çoğaltılan lisans ve doktora tezleri, seminer, sempozyum bildirileri ve raporlar gibi gri yayınlara ulaşma; kaynakların dijital ortamlara aktarımı; elektronik iletişim ağlarına ve kaynaklarına erişim; kullanıcılara yönelik çevrim içi oryantasyonlar ve eğitimler; web tabanlı belgeler, elektronik kitaplar ve tam metinlere erişim gibi çeşitli hizmetler olarak sıralanabilmektedir (Rusbridge 1998).

Artık kütüphaneler için bir rutin haline gelen duyuruların web sayfası aracıllğıyla yapılması başta olmak üzere, elektronik kaynakların tümüne web sayfasından ulaşabilme ve diğer web hizmetleri, kullanıcıların web sayfalarına olan ilgisini ve kullanımını artırmakta hatta kütüphaneden web sayfası vasıtasıyla yararlanma, fiziksel olarak yararlanmanın önüne geçmektedir. Zira günümüzde kütüphaneye gitmeden kütüphane kataloğuna erişimin sağlanması, kitaplar arasında dolaşılması ve istenen kaynağın içeriğine/içindekilerine erişimin sağlanması gibi işlemler sanal ortamda kolaylıkla yapılabilmektedir.

\section{Kütüphanelerin Toplumsal İletişim Amacıyla Kullanımı}

Kişiler arası ilişkilerin temelini oluşturan iletişim, kişiden kişiye, kişiden gruba, gruptan kişiye ya da gruptan gruba bilgi, tutum ve davranışların uygun ortamlar ve kanallar kullanılarak aktarılmasıdır. Toplumun çevresi ile bütünleşmesini sağlayan toplumsal (kitlesel) iletişim, çoğunlukla kitle iletişim araçlarının kullanımıyla kitleler arasında gerçekleşen bir iletişim türüdür (Aziz 2010, 99-102). Günümüzde kitle iletişim araçları, kişiler için birer referans noktasına dönüşmekte ve hemen her alanda temel bilgi kaynağı olmaktadır. Toplumsal yaşamın önemli ve zorunlu bir unsuru olan toplumsal iletişimin değeri ve etkisi gün geçtikçe artmaktadır. Bu nedenle toplumu oluşturan tüm örgütlerin bu kavrama gereken ehemmiyeti vermesi gerekmektedir.

Örgüt, maddi ürünler üreten bir yap1 olabileceği gibi düşünce, eğlence ve dinlenme ile ilgili sosyal, ekonomik, siyasal ve kültürel bir yap1 da olabilir (Erdoğan 2013, 110). Kütüphaneler, insanların bilgi ve belge gereksinimlerini karşıladıkları, diğer bir deyişle bir hizmet yerine getirdikleri için hizmet üreten örgütlerdir. Genellikle bir kamu kurumu bünyesinde yer alırlar ve kâr amacı gütmezler (Kurulgan 2015, 33). Toplumsal kurum olarak kütüphaneler; kullanıc1, kütüphaneci, derme, bütçe ve bina gibi unsurların bir araya gelmesi sonucunda oluşmaktadır. Kütüphane kurumu, belirli gereksinimleri karşılamak amaciyla oluşturulmuş ve belirli bir amaca hizmet eden bir sistemdir. Kütüphane sisteminin amacı, insanların gereksinim duyduğu bilgi ya da bilgi kaynaklarına erişim sağlamalarına ve bunları kullanmalarına olanak sağlayacak faaliyetlerde bulunmaktır (Yılmaz 2006). Kütüphane; bilginin yer aldığı kaynaklar, bilgi kaynaklarına ihtiyacı olan kişiler ve bilgi kaynağı ile kişiler arasındaki ilişkiyi kapsayan bir üçgene benzetilebilir. Bu kapsamda kütüphanelerin varllğı, hizmet verdikleri toplumun ihtiyaçları ve talepleri doğrultusunda örgütlenmeleri sayesinde gerçekleşebilecektir. Bu gereklilik, kütüphanede aktif ve potansiyel kullanıcı grupları ile yoğun ve devamlı iletişimi zorunlu hale getirmektedir.

Kütüphanenin var oluş amacı olan bilgi kaynaklarına erişim, statik (durağan) ve tek yönlü iletişim biçimindeydi. Bilginin yayılması için kullanılan geleneksel yöntemler, e-posta gibi dijital teknolojiyi içerenler bile tek yönlü iletişim şeklindeydi (Rodriguez 2010, 108). Ancak dijital iletişim olanakları ve araçları ile birlikte bu durum değişmektedir. Sosyal medya çağına dönüşüm sürecinde kütüphaneler, çevrim içi ortamı aktif biçimde bir iletişim arac1 olarak kullanmaya başlamışlardır. Bugünün kütüphane kullanıcıları, ulaştıkları bilgi kaynaklarına yorum yapmak, gerekirse düzenlemek ve gözden geçirmek arzusundadır (Einasto 2015, 252). Yine kullanıcılar, içeriği bağımsız biçimde denetlemek ve okuma deneyimlerini diğer kullanıc1- 
larla paylaşmak istemektedir. Dolayısıyla kütüphanelerin hâkimiyet ve kontrol arayışı yerine entegrasyona odaklanmaları gerekmektedir. Kütüphane projeleri, hizmetleri ve politikaları, kullanıcı katılımlı ve diyaloğa dayalı yeni bir etkileşim türünü oluşturmaktadır. Yeni iletişim türü, yeni bir iletişim stratejisi tasarlayarak kullanıcılarla aktif biçimde iş birliği yapılması anlamına gelmektedir (Neal 2011, 68). Bu kapsamda kütüphane, kitle iletişimi boyutunda veri aktarımının sağlandığı bir kanal görevi görmektedir. Kütüphaneler, sundukları hizmetler ve düzenledikleri toplumsal etkinlikler ile boş zamanları değerlendirme ve eğlendirme imkânları sunmalarıyla toplumsal iletişimin bir parçası olmaktadır (Yılmaz 2003, 23).

Bugün kütüphanelerde gerçekleşen iletişimde anahtar kavram; yatay, dengeli ve iki yönlü bir iletişim olarak ifade edilen diyaloğa dayalı bir katılımdır (Einasto 2015, 252). Ancak bu durum planlı iletişim çalışmaları sayesinde gerçekleşebilecektir. Kütüphaneler için bir iletişim stratejisi oluşturmak, kütüphanelerin tüm farklı iletişim planlarına tutarlılık kazandırmaya yardımcı olacaktır. Böyle bir stratejiyle kütüphanelerin kendi amaçları ve faaliyetleri ile kullanıcıların beklentilerini ve ihtiyaçlarını bağdaştırabileceklerdir. Kütüphaneler, stratejik planlama düzeyinde bir iletişim stratejisi hazırlayarak proaktif, iyi koordine edilmiş ve kendilerine yarar sağlayacak iletişim ortamı oluşturabilirler. Kriz durumlarına yol açabilecek sorunları önceden tahmin ederek ve tespit ederek, rekabet avantajı kazanabilir ve yaşanan sorunları daha etkili bir şekilde çözüme kavuşturabilirler. Dolayısıyla etkin bir iletişim stratejisi, kütüphanenin verimli ve rekabetçi bir şekilde çalışabilme yeteneğinin merkezinde yer almaktadır (Kuchi 2006, 219).

$\mathrm{Bu}$ bağlamda kütüphanelerde iletişim faaliyetleri, toplumu bilgilendirmek ve faaliyetlerini benimsetmek, toplumun kütüphaneye karşı olumlu davranışlar sergilemesini sağlamak, alınacak kararların doğruluk derecesini artırmak, toplumla iş birliği yaparak kütüphane hizmetlerinin hızl1 ve kolay biçimde yürütülmesini sağlamak, toplumun beklentilerine yanıt vermek üzere örgütlenmelidir. Öte yandan iletişim, kütüphanenin paydaş desteği almasına, yaşanan çatışmaları ve değişimi yönetmesine yardımcı olmaktadır (Kuchi 2006, 219). Kütüphanenin kendisini kullanıcılarına tanıtması/anlatması ve kullanıcılarını tanıması/anlaması ancak iletişim ile gerçekleşeceğinden kütüphane, kullanıcılarının kütüphane hizmetleri hakkında ne düşündüğünü anlayabilmek için tüm kullanıcılarını dinlemeli ve kullanıcılarla onların anlayacağı yollar ve yöntemler yardımıyla iletişim kurmalıdır (Holt 2007, 121). Böylece kütüphanenin büyümesine ve başarısına katkı sağlayacak, kütüphaneye mali ve duygusal destek verecek, kütüphaneye ilgi duyan kitlelerle karşılıklı ve olumlu ilişkiler geliştirilebilecektir (Marshall 2001, 116).

\section{Sonuç}

Toplumsal iletişim ve kütüphaneler arasındaki ilişki, farklı boyutları ile incelebilmektedir. Bu incelemenin başlica hedefi, kütüphanelerin toplumsal iletişim süreci içinde değerlendirilme zorunluluğudur. Diğer bir deyişle kütüphane ve toplumsal iletişim ilişkisinin kesiştiği temel noktaları tespit edebilmektir. Bu noktaların tespit edilmesi ile toplumsal iletişimin kütüphaneler üzerindeki etkilerinden yararlanarak kütüphanelerin toplum tarafından kullanılmasını sağlamak ve kullanım oranını artırmak mümkün olacaktır. Zira kütüphaneler, toplumsal iletişim sürecinin bir unsuru olarak her çeşit bilgiyi ve bilgi kaynağını bireylere sunarak, bireylerin bilgi ihtiyacını karşılamakta böylece toplumsal iletişimin gerçekleşmesinde önemli bir rol üstlenmektedir. Kütüphaneler, hizmet verdikleri kullanıcılarla ve hizmet götürdükleri toplumla iletişim kurarak, kütüphane kurumunun gelişimine katkı sağlayacaktır.

Kütüphanelerde toplumsal iletişimden yararlanabilmek ve bu yönde çalışmalarda bulunmak için gerekli birtakım unsurlar ve/veya şartlar yerine getirilmelidir. Öncelikle kütüphanenin aktif ya da pasif olan kullanıcıları ile potansiyel kullanıcıları incelenerek, tüm gruplarla etkin iletişim kurulmalı ve kurulan iletişim kesintisiz devam ettirilmelidir. Bu sürecin en önemli yararı, kul- 
lanıcılardan geri bildirim alınması, kullanıcıların taleplerini, önerilerini ya da şikâyetlerini öğrenme imkânı sağlamasıdır. Böylece elde edilen veriler doğrultusunda hizmetler gözden geçirilebilir ve gerekli düzenlemeler yapılabilir. Diğer önemli konu ise kullanıcılara ulaşmak için her tür (geleneksel ya da web tabanlı) iletişim aracından faydalanılması ve bu araçlarla iletişim kurulmasıdır. Kitlesel iletişim araçları yanında kütüphane web sitesi, bloglar ve diğer sosyal medya ortamlarının etkin biçimde kullanılması önemlidir.

Kütüphaneler aracılığıyla gerçekleşen toplumsal iletişim sayesinde toplumu kütüphane hizmetlerinden aktif olarak faydalandırmak, toplumsal iletişimi yaygınlaştırmak ve sağlıklı biçimde yürütmek, sunulan bilgi hizmetlerinin devamlılığını sağlamak gibi çeşitli faydalar elde etmek mümkündür. Öte yandan kütüphanelerde verilen hizmetlerde müşteri memnuniyeti anlayışının temel alınması ve bu anlayışla hizmet planlaması yapılması önem taşımaktadır. Bu kapsamda kütüphanelerin, etkili bir toplumsal iletişim için kullanıcıları ile iyi ilişkiler kurması, kullanıcıların düşüncelerine önem vermesi, kullanıcılardan geri bildirim alması, kütüphanedeki gelişmelerden ve yeniliklerden kullanıcılarını haberdar etmesi gerekmektedir. Kütüphaneler, toplumsal iletişime ve topluma dönük hizmetlerde iletişim olgusuna hâkim olabilirse topluma yön veren kurumlardan biri haline gelebilir. 


\section{KAYNAKÇA}

Afolabi M. (1993). “Application of Johari Communication Awareness Model to Special Libraries Management”. Library Management 14/1 (1993) 24-27. Doi:10.1108/01435129310023475

Agyemang F. G., Boateng H. \& Dzandu M. D. (2015). "Dialogic Communication on Universities in Ghana Libraries’ Websites”. The Electronic Library 33/4 (2015) 684-697. Doi:10.1108/El-02-2014-0041

Alansari H.A. (2013). "Public Relations in Academic Libraries in Gulf Cooperation Council (GCC) States”. Library Management 34/1-2 (2013) 68-82. Doi:10.1108/01435121311298289

Aziz A. (2010). Illetişime Giriş. İstanbul 2010.

Bernaoui R. \& Hassoun M. (2015). “Algerian University Libraries and The Digital Age: New Communication Behaviors”. Library Management 36/1-2 (2015) 58-69. Doi:10.1108/Lm-09-2014-0114

Bonk K., Tynes E., Griggs H. \& Sparks P. (2008). Strategic Communications for Nonprofits: A Step-ByStep Guide to Working with the Media. San Francisco 2008.

Brophy P. (2007). “Communicating the Library: Librarians and Faculty in Dialogue”. Library Management 28/8-9 (2007) 515-523. Doi:10.1108/01435120710837792

Bryson J. M. (2011). Strategic Planning for Public and Nonprofit Organizations: A Guide to Strengthening and Sustaining Organizational Achievement. San Francisco 2011.

Budd J. M. \& Velasquez D. L. (2014). "Phenomenology and Organizational Communication”. New Library World 115/7-8 (2014) 394-404.

Can H. (1999). Organizasyon ve Yönetim. Ankara 1999.

Costello K. \& Bosque D. D. (2010). "For Better or Worse: Using Wikis and Blogs for Staff Communication in An Academic Library”. Journal of Web Librarianship 4/2-3 (2010) 143-160. Doi:10.1080/19322909.2010.502877

Dilenschneider R. L. (2010). The AMA Handbook of Public Relations. New York 2010.

Drivas I. C., Sakas D. P. \& Giannakopoulos G. A. (2016). "Self-Other Agreement for Improving Communication in Libraries and Information Services”. Library Review 65/3 (2016) 206-223. Doi:10.1108/Lr-06-2015-0064

Einasto O. (2015). “Transforming Library Communication: From Gutenberg To Zuckerberg”. New Library World 116/5-6 (2015) 247-263.

Erdoğan İ. (2002). Illetişimi Anlamak. Ankara 2002.

Erdoğan İ. (2013). Medya Sosyolojisi. Eskişehir 2013.

Farkas M. G. (2007). Social Software in Libraries: Building Collaboration, Communication, And Community Online. New Jersey 2007.

Gökçe O. (2010). Illetişim Bilimine Giriş. Konya 2010.

Gould M. R. (2009). The Library PR Handbook: High-Impact Communications. Chicago 2009.

Grgic I. H. (2013). “Croatian School Libraries on Facebook: Meeting the Needs of Young Library Users”. New Library World 114/9-10 (2013) 416-427. Doi:10.1108/Nlw-01-2013-0010

Güçdemir Y. (2010). Sanal Ortamda İletişim: Bir Halkla İlişkiler Perspektifi. İstanbul 2010.

Güngör N. (2011). Illetişime Giriş. Ankara 2011.

Gürgen H. (1997). Örgütlerde İletişim Kalitesi. İstanbul 1997.

Holt G. (2007). “Communicating the Value of Your Libraries”. The Bottom Line 20/3 (2007) 119-124. Doi:10.1108/08880450710825833

Hughes C. A., Rockman I. \& Wilson L. A. (2000). “Communicating Resource Needs for Successful Library Services”. The Bottom Line 13/1 (2000) 10-15. Doi:10.1108/08880450010310453

Jankowska M. A. \& Marshall L. (2004). "Why Social Interaction and Good Communication in Academic Libraries Matters”. The Reference Librarian 40/83-84 (2004) 131-144. Doi: 10.1300/J120v40n83_11

Kuchi T. (2006). "Constant Change and The Strategic Role of Communication: A Selective Annotated Bibliography”. Library Management 27/4-5 (2006) 218-235. Doi:10.1108/01435120610668160

Kumtepe G. E. \& Küçük M. (2015). "İletişim İşlevleri Sormacasının Türkçe Versiyonu için Geçerlik ve Güvenirlik Çalışması”. Selçuk İletişim 8/4 (2015) 5-31. 
Kurulgan M. (2015). Çăğdaş Bilgi-Belge Merkezlerinde Yönetim ve Organizasyon: Literatüre Yönelik Karşılaştırmalı Bir Analiz. Ankara 2015.

Li Y., Wong I.S.M. \& Chan L.P.Y. (2010). “Mylibrary Calendar: A Web 2.0 Communication Platform”. The Electronic Library 28/3 (2010) 374-385. Doi:10.1108/02640471011051963

Li Z. (2006). “Communication in Academic Libraries: An East Asian Perspective”. Reference Services Review 34/1 (2006) 164-176.

Marshall N.J. (2001). "Public Relations in Academic Libraries: A Descriptive Analysis”. The Journal of Academic Librarianship 27/2 (2001) 116-121. Doi:10.1016/S0099-1333(00)00183-X

Mcintyre A. \& Nicolle J. (2008). “Biblioblogging: Blogs for Library Communication”. The Electronic Library 26/5 (2008) 683-694. Doi:10.1108/02640470810910701

Moriarty S., Mitchell N. \& Wells W. (2012). Advertising \& IMC: Principles and Practice. New Jersey 2012.

Neal J.G. (2011). “Advancing from Kumbaya to Radical Collaboration: Redefining The Future Research Library”. Journal Of Library Administration 51/1 (2011) 66-76. Doi: 10.7916/D8fj2ss5

Nielsen H. J. (2009). "Library Communication Outside a Library Context: Instant Messaging as Library Service”. New Library World 110/5-6 (2009) 237-248. doi:10.1108/03074800910954262

O’hair D., Friedrich G. W. \& Dixon L. D. (2005). Strategic Communication in Business and the Professions. Boston 2005.

Parrott J. (2016). "Communication and Collaboration in Library Technical Services: A Case Study Of New York University in Abu Dhabi”. New Review of Academic Librarianship 22/2-3 (2016) 294303. Doi:10.1080/13614533.2016.1181663

Patterson J. \& Radtke J. M. (2009). Strategic Communications for Nonprofit Organization: Seven Steps to Creating a Successful Plan by Patterson. New Jersey 2009.

Poe M. T. (2014). Illetişim Tarihi: Konuşmanın Evriminden İnternete Medya ve Toplum. İstanbul 2014.

Rodriguez J. (2010). "Social Software in Academic Libraries for Internal Communication and Knowledge Management: A Comparison of Two Reference Blog Implementations”. Internet Reference Services Quarterly 15/2 (2010) 107-124. Doi:10.1080/10875301003788323

Rukancı F. \& Anameriç H. (2004). "Bilgi Toplumu ve Toplumun Bilgilenmesinde Kütüphanelerin Rolü”. Yay. Haz. Arslantekin \& F. Özdemirci, Kütüphaneciliğin Destanı Uluslararası Sempozyumu Bildiriler 21-24 Ekim 2004 (2004) 330-338. Ankara.

Rusbridge C. (1998). “Towards the Hybrid Library”. D-Lib Magazine. Source:_<http://www.Dlib.Org/ Dlib/July98/Rusbridge/07rusbridge.html>.

Sabuncuoğlu Z. \& Gümüş M. (2008). Örgütlerde İletişim. İstanbul 2008.

Siess J. A. (2003). The Visible Librarian: Asserting Your Value with Marketing and Advocacy. Chicago 2003.

Te’eni D. (2008). “Organizational Communication”. Knowledge Management: Concepts, Methodologies, Tools and Applications (2008) 3004-3012. London.

Tutar H. (2009). Örgütsel İletişim. Ankara 2009.

Usluata A. (1995). İletişim. İstanbul 1995.

Wallis R. (2005). “Project Bluebird: Research into Better Library Communication”. Library Hi Tech News 22/6 (2005) 15-16. Doi:10.1108/07419050510620244

Walter (2018). "Communicating Value Through Strategic Engagement: Promoting Awareness of The Value of Libraries Through Alignment Across Academic, Student, and Administrative Affairs”. Library Management 39/3-4 (2018) 154-165. Doi:10.1108/Lm-09-2017-0093

Yatkın A. (2003). Halkla İlişkiler ve Illetişim. Ankara 2003.

Y1lmaz B. (2003). “Toplumsal İletişim ve Kütüphane”. Hacettepe Üniversitesi Edebiyat Fakültesi Dergisi 20/2 (2003) 11-29.

Yılmaz E. (2006). “Kütüphanelerde Halkla İlişkiler Çalışmaları ve Türkiye’de Durum”. Verimlilik Dergisi 1(2006). 